Received: December 14, 2017

\title{
Animation Development in Multimedia Teaching Software Based on Multimedia Tool Book
}

\author{
Jian Wang ${ }^{1}$ \\ Jingdezhen Ceramic Institute
}

\author{
Lu Wang ${ }^{2}$ \\ Jingdezhen Ceramic Institute
}

\begin{abstract}
As the latest technology in the computer industry, multimedia has brought about a revolution in information dissemination technology, and it has achieved rapid development since its inception. It has provided new means for the reform of education and has injected new vitality into it, which has had a profound impact on the modernization of education. Animation is an important content to be considered in the production of multimedia courseware. This article discusses the characteristics of animation, the theoretical basis of the application of the courseware, and the existing problems. The development of equipment-assisted teaching aid system has opened up a new path for the training of new equipment. It has received good results through several years of teaching practice. It fully embodies the powerful advantages of ToolBook in the field of multimedia teaching. With the arrival of computer networking, multimedia training will have a major impact in the field of education and training.
\end{abstract}

\section{Keywords}

Information Dissemination • Reform of Education • Multimedia • Education and Training • Toolbook

\footnotetext{
${ }^{1}$ Correspondence to: Jian Wang (PhD), Jingdezhen Ceramic Institute, Jingdezhen 333403, China. Email: tapias@163.com 2 Jingdezhen Ceramic Institute, Jingdezhen 333403, China. Email: aolifu2018@163.com 
In multimedia courseware, more and more animation materials are used. Animation is the use of human visual persistence features, but also it includes the screen zoom, rotation, transform, fade in, fade out and other special effects. Appropriate use of animations can enhance the visual effects of multimedia software and serve to emphasize topics. Multimedia technology is the fastest growing and most active technology in the field of information technology today, and it is the focus of the development and the new generation of electronic technology (Babiker, 2015; Svirko \& Mellanby, 2017). Multimedia technology integrates computer, sound, text, graphics, animation, video, and communications into a whole. With the increasingly popular high-speed information network, it can realize the global networking of computers and the sharing of information resources. Therefore, it is widely used in consulting services. Books, education, communications, military, finance, medical, and many other industries are subtly changing the face of our lives.

To talk about the past, present, and future of multimedia, we must first know what the multimedia is. Because the multimedia content is too wide, and the application field is too wide, no one can define a very precise and clear definition (Svirko \& Mellanby, 2017). The "multiple" of multimedia is its multi-media performance, a variety of sensory roles, a variety of devices, multi-disciplinary convergence, and multi-domain applications; "media" refers to the intermediary between people and objective things; "body" is the integration of its words, integrated integration. No one can now define a very precise and clear definition. The "multiple" of multimedia is its multi-media performance, a variety of sensory roles, multiple devices, multidisciplinary convergence, and multi-field applications; "media" refers to the intermediary between man and objective things; the "body" is the integration and integration of words. At present, most of the multimedia use only human visual and auditory.

\section{The diversity of multimedia animation performance}

\section{The multimedia animation}

Diversity means that multimedia is the integration and use of multiple media. For example, the case of a movie has played on a computer, a comprehensive multimedia technology that realizes a variety of media, such as a sound image animation, is integrated, interactive, intelligent, easy to expand, synergistic, and real-time in addition to the diversity of the information carrier. Integrated digital signal can comprehensively process text, sound, graphics, animation, images, video and other information, and organically they combine these different types of information (Canclini, 2013; Park, Kim, Cha \& Nam, 2014). Interactivity Information has organized in a hypermedia structure that facilitates human-computer interaction. Figure 1 shows the multimedia information in network. In other words, people can actively choose and accept information according to their own habits according to their own habits, and draw up the path of viewing content. Intelligence provides an easy-to-use, user-friendly interface that makes the computer more intuitive, more convenient, more intimate, and more user-friendly. It can be easily connected to various external devices for data exchange, monitoring and control. In addition, the use of digital information effectively solves the problem of distortion of data during processing and transmission. Coordination among multiple media and coordination of time, space, and content 
is one of the key technologies for multimedia. Real-time performance means that in a multimedia system, there is a close relationship both in time and in space, and it is a group with synchronization and coordination.

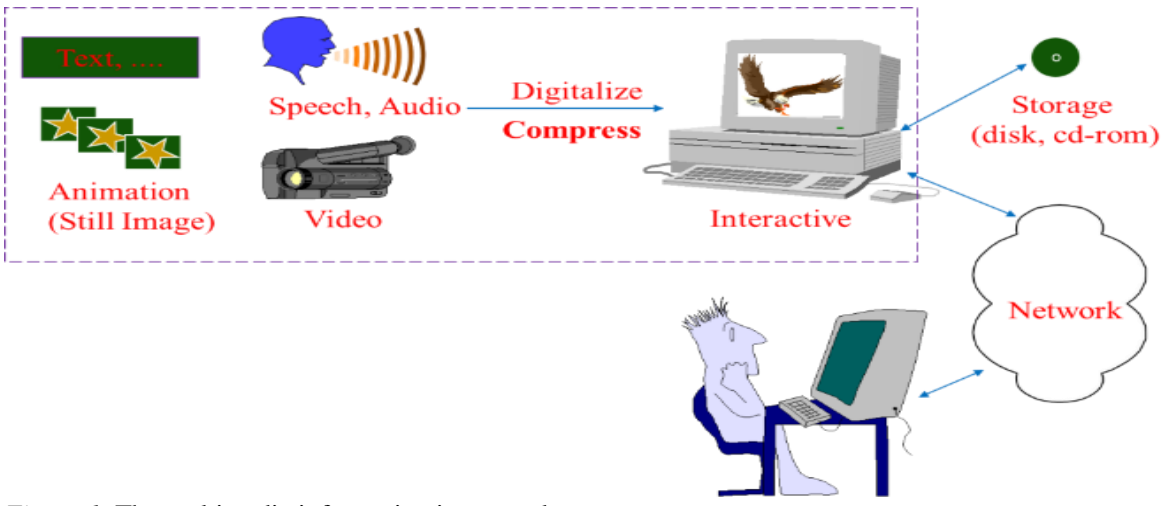

Figure 1. The multimedia information in network.

\section{The characteristics of computer}

In multimedia courseware, to use computer animation reasonably, you should first understand the characteristics of computer animation and use the advantages of animation. Figure 2 shows the characteristics of computer animation.

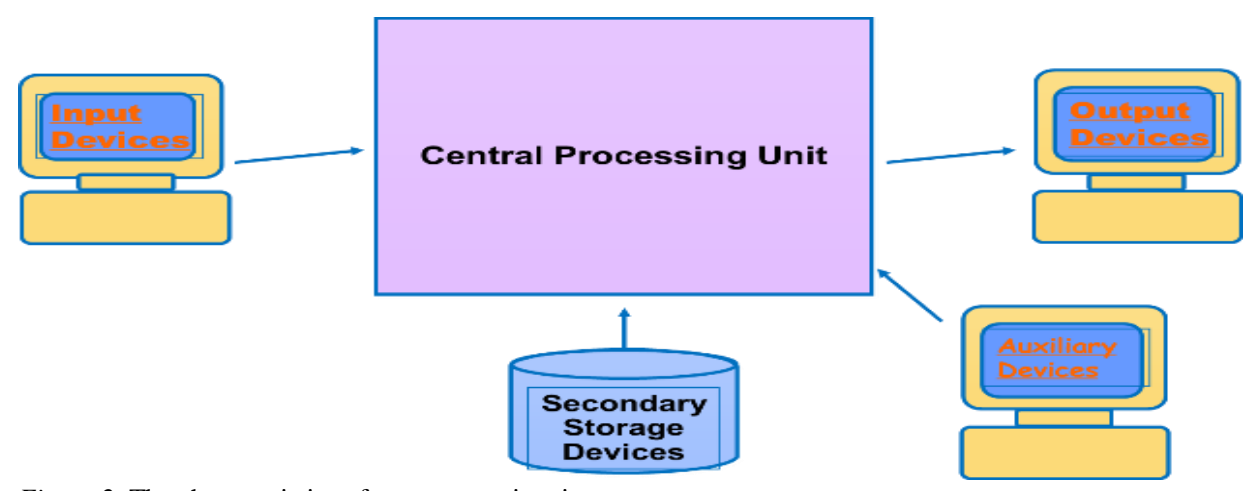

Figure 2. The characteristics of computer animation.

\section{Mainly based on visual images}

Computer animation is a kind of visual image, which mainly displays moving information. Computer animation uses computer technology to generate image motion. Whether it is two-dimensional animation or three-dimensional animation, image symbols are used to present teaching information, and audio explanations and written explanations play a supporting role (Alsawaie \& Alghazo, 2010). The words in the article are composed of sentences; many sentences compose paragraphs to illustrate the problem. Computer animation is 
through expressive pictures, and many pictures are concatenated together to represent teaching information. Expressive computer animation can be used without commentary or subtitles to explain.

In addition, computer animation has based on moving images to present teaching information. Figure 3 is the multimedia courseware based on visual images. If the educational information represented by the animation is only or most of the still image images, the information have compiled into a slide projection teaching material, which is beneficial for reducing costs and facilitating use. Computer animation is obtained through key frames and related algorithms. It is an important feature to present teaching information based on moving images.

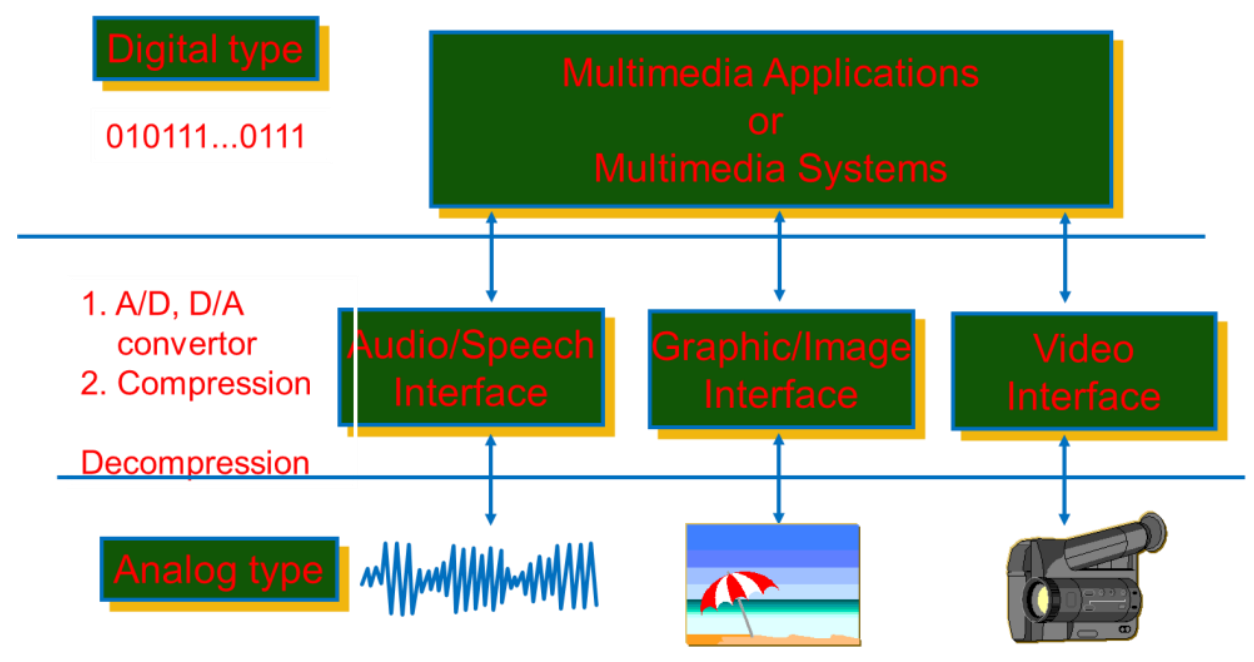

Figure 3. Multimedia courseware based on visual images.

\section{Using animation to present the essential characteristics of things}

In multimedia courseware, animations can be used to dynamically simulate and demonstrate some of the changes in theory and phenomena that cannot be observed or abstracted in real life and are difficult to express experimentally (John, Ray \& Sun, 2013; Daniel et al., 2018; Vatansever \& Yalcin, 2017). Through animation, the abstract content can be visualized, making many difficult-to-understand teaching content vivid and interesting, and achieving a multiplier effect.

\section{Combine with sound and other media to transmit information in multiple dimensions}

People use verbal language to express information, which is a statement followed by a statement in a linear manner. People receive the speech signal with their ears is also a sentence to listen to linearly. Similarly, the word language symbol is a form of writing of the spoken language symbol, which is used linearly when people use it to transmit and receive information. 
Animations have distinguished from linguistic symbols by the transmission of information in image symbols. It is not linear but multi-dimensional. The images presented on the computer screen, we do not have to look at it in a row, but a complete picture. Not only can you see the plane, the three-dimensional, but also the colour, any movements and changes (Nuninger \& Châtelet, 2018; Usai, O'Neil \& Newman, 2018). Computer animation has often accompanied by explanations, sounds, and music to supplement and enhance the information transmission effect when presenting teaching information. It allows learners to use both visual and auditory organs for learning in figure 4 .

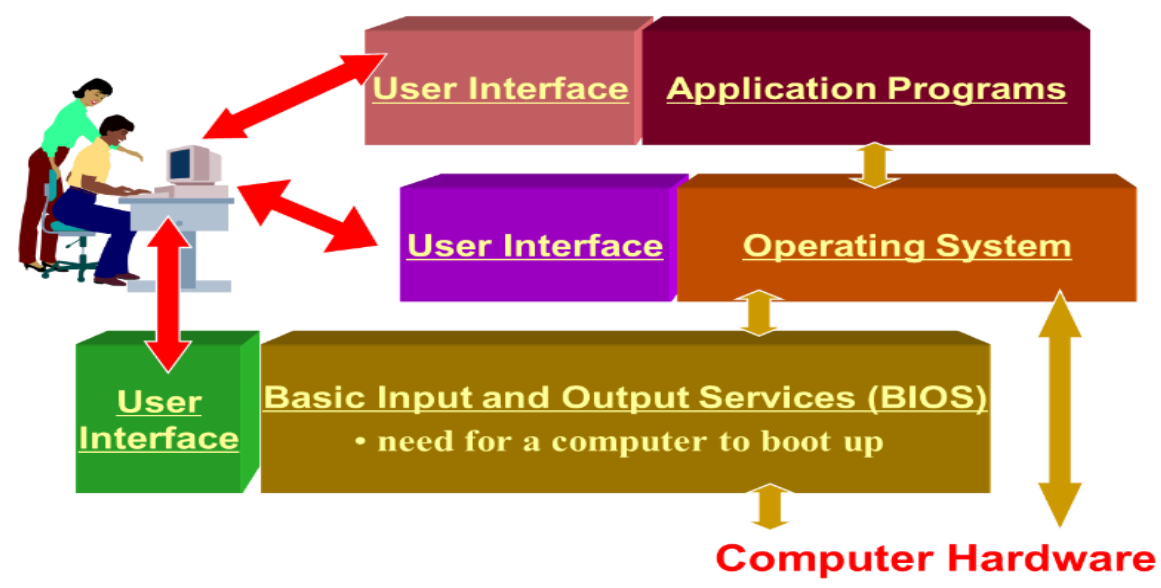

Figure 4. Multimedia hardware based on Animations

\section{Virtual Reproduction, Overcoming Temporal and Spatial Limitations}

Computer animation can reproduce or create a vivid and vivid image or scene with emotional colour, so that students can learn knowledge, be infected, and educated in a pleasant atmosphere; can imitate natural phenomena, state of motion and process, reveal their laws, and break through time and space, Micro and macro restrictions on teaching experimental conditions. Computer animation can be saved in AVI, MOV, FLC, MPG, WRL, and other formats (Cassino, Tucci, Vitiello \& Francese, 2015). It can be recorded on computer disk, VCD, DVD, video tape, and other storage media. It can be played on a computer stand-alone computer or on a LAN or WAN. Computer animation is suitable for a variety of teaching and learning methods. (1) Self-learning methods. The learner learns at the resource centre or at home using the corresponding playback device. (2) Classroom teaching methods. Teachers teach in the MPC classroom or on the LAN.

\section{Methodology}

ToolBook is an object-oriented multimedia development tool launched by American Symeontrix. Like the software name, the process of making multimedia courseware with ToolBook is like writing a book: first build the overall framework of a book, and then add the page to the book. Then, put the text, stubbornness, buttons 
and other objects into the page, and then use the system provided programming language Openscnript to write a script to determine the role of various objects in the courseware. During playback, when the object has triggered in some way, the script accompanying the object performs the corresponding operation. Although this kind of "e-book" is somewhat complicated to produce, it has strong expressiveness and interactivity, and the produced program has great flexibility and flexibility. It is suitable for creating feature-rich multimedia courseware and multimedia books. Figure 5 is the ToolBook license GUI. In particular, ToolBook version 4.0 has added a powerful courseware development tool set and course management system because of the original, providing greater convenience for producers. In addition, the company also launched the ToolBook II, which provides a solution for distributed teaching in the Internet environment.

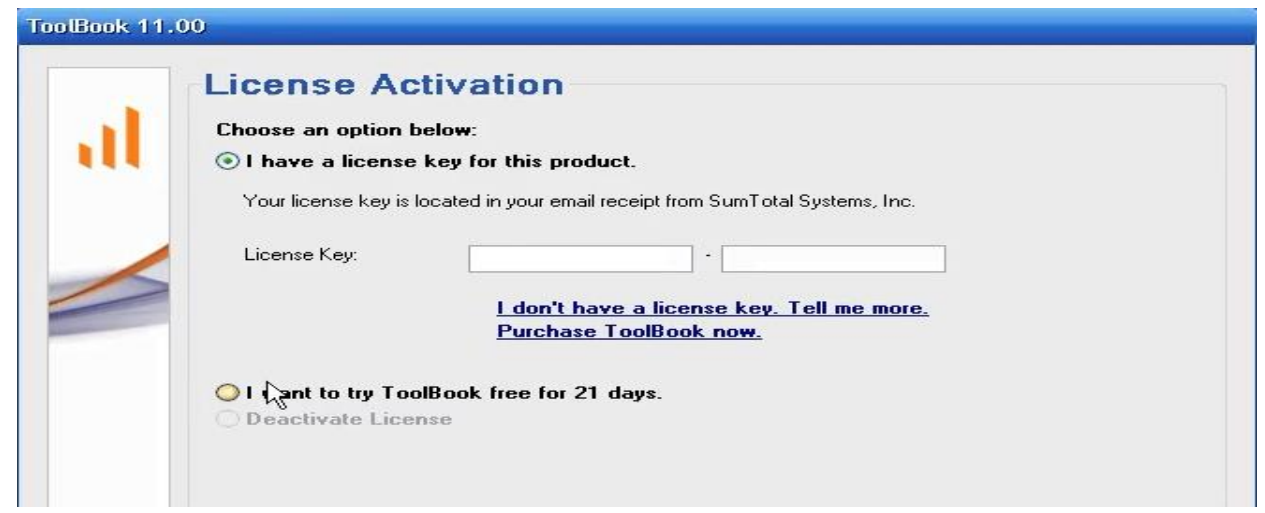

Figure 5. ToolBook license GUI.

ToolBook II is the second generation of ToolBook series launched by the United States. ToolBook I is built on the basis of first-generation multimedia product creation. It not only retains the full functionality of the first generation of ToolBook products, but also adds a powerful Internet function. ToolBook cannot only develop Multimedia Applications software based on Windows. ToolBook I use the ability of Internet to provide an easy low-cost solution that can be trained and taught anywhere in the world, and information can be updated at any time. ToolBook I includes various tools for creating, managing, and accessing distributed learning applications. It includes the world's first Distribute the creative environment for training and educational applications in the Internet internal format (Brutus \& Livers, 2010; Jahangiri \& Abilipour, 2014). ToolBook I is not just a creative environment, but it is the only program that provides a server-based curriculum management system. It makes full use of the provided interactive and two-way communication functions; only in this case, "Certified understanding" becomes possible. The teacher cannot only confirm whether the student sees the teaching content, but also can understand the student. Due to the unique performance of ToolBook 1, it is especially suitable for production: multimedia interactive learning courseware, multimedia information inquiry system, multimedia standard test, and multimedia electronic books. 


\section{Collection and preparation of multimedia materials}

\section{Preparation of text}

The text in the multimedia material library has mainly used to present the title, button name, menu name, and teaching content. It is the main component of the material library, and mainly adopts the following two forms. (1). Ordinary text. Enter text content directly in the system-authoring environment, or create text files or Rich Text format files (RTE format) through external text editing software (such as WPS, WORD, etc.). The purpose of these two methods is different. The text files that have input in the authoring environment have mainly used for small texts. If a large amount of text input is required and the display of the text requires certain conditions, then an external file or RTE file should have considered for ToolBook external production. (2). ToolBook Graphic text. Graphic files have actually attributed to graphics classes, called graphical text. Graphic material has a large amount of material, but it has its own advantages. It can perform special effects on graphic text, such as transparent words, three-dimensional characters, gradient words, and so on. Graphic text is both artistic and appealing [16]. Graphical text in a multimedia library can be created in a paintbrush or graphics software such as Photoshop 5.0.

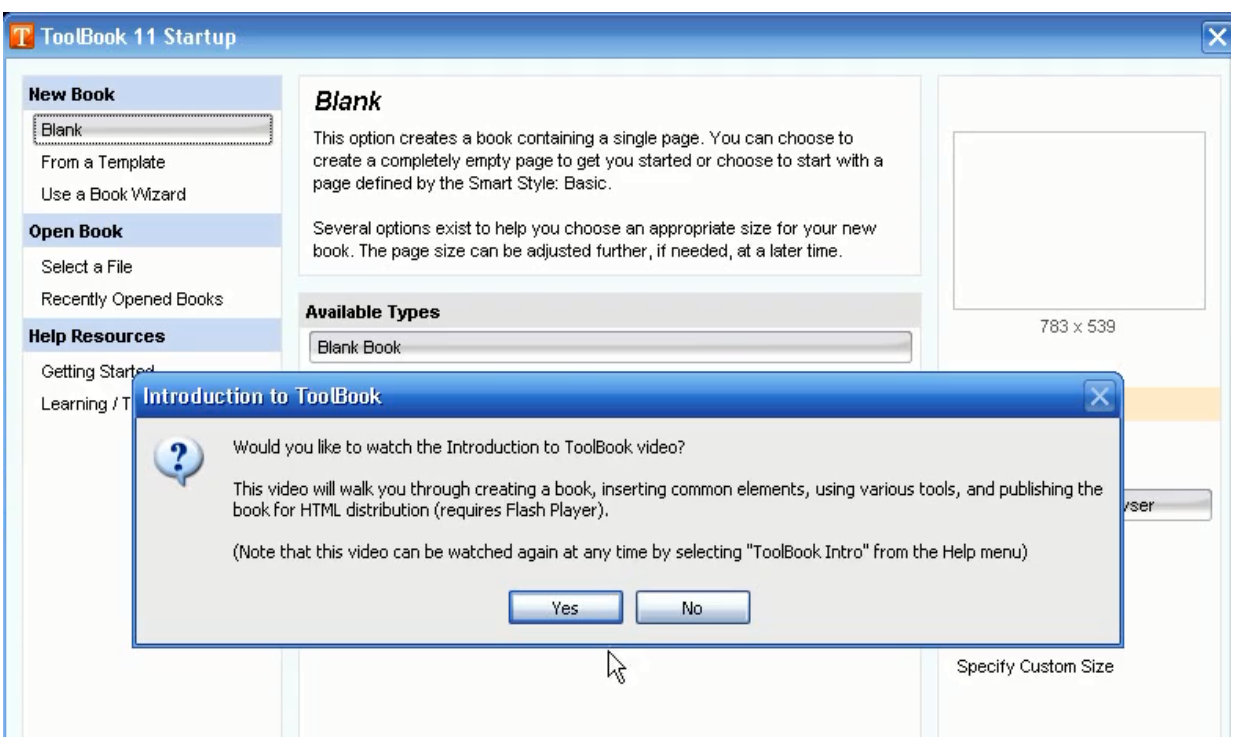

Figure 6. ToolBook Image preparation GUI.

\section{ToolBook Image preparation}

The images in the multimedia material library have mainly used for backgrounds, illustrations, graphic interaction areas, and graphic buttons. The following methods in ToolBook can be used. The background image, button graphic, and cursor graphic in the multimedia material library have selected from the material library. It 
is usually stored on a hard disk or CD-ROM. From this, we can pick out many images that are suitable for multimedia library use. The illustrations of the teaching content in the multimedia material library have obtained through this method. Windows Brush (Paintbrush) or professional drawing software Painter, CorelDraw, needs to draw simple strokes in multimedia teaching software directly in the computer. For some icons, button graphics and other materials, a special application (such as Piazzus) has generally used to capture the screen. Image composition in the multimedia material library can have performed in image software such as Photoshop and PhotoStyle. In the multimedia material library can use professional animation software 3Dstudio Max to create three-dimensional characters and simulation objects. Figure 6 give the ToolBook Image preparation GUI.

\section{Preparation for ToolBook animation}

Animation is a simulation of the movement of things and the process of change. The animation in the multimedia material library is both two-dimensional and three-dimensional. Therefore, it has implemented using two software tools, Animator Pro and Director. Animator Pro is a professional animation tool that generates traditional animations, bitmap animations, film animations, morph animations, text animations, and color animations. Although the Director is a multimedia authoring tool, the products produced in the Director can generate animation files, and the Director itself has strong animation production capabilities. Therefore, you can use Director to create two-dimensional animation. Compared with two-dimensional animation, threedimensional animation, in addition to the characteristics of two-dimensional animation X-Y plane, also increases the depth dimension, through the material processing, resulting in a sense of texture of the moving object, under the action of the light and the camera, the movement effect is very realistic. The 3D animation in the multimedia material library has created in 3Dstudio Max. 3Dstudio Max's animation is very powerful, the colour output is faster, and the final animation file, in addition to the description of the motion process integrates the sound elements to enhance the animation performance. In addition, we can also write animation programs directly in programming languages.

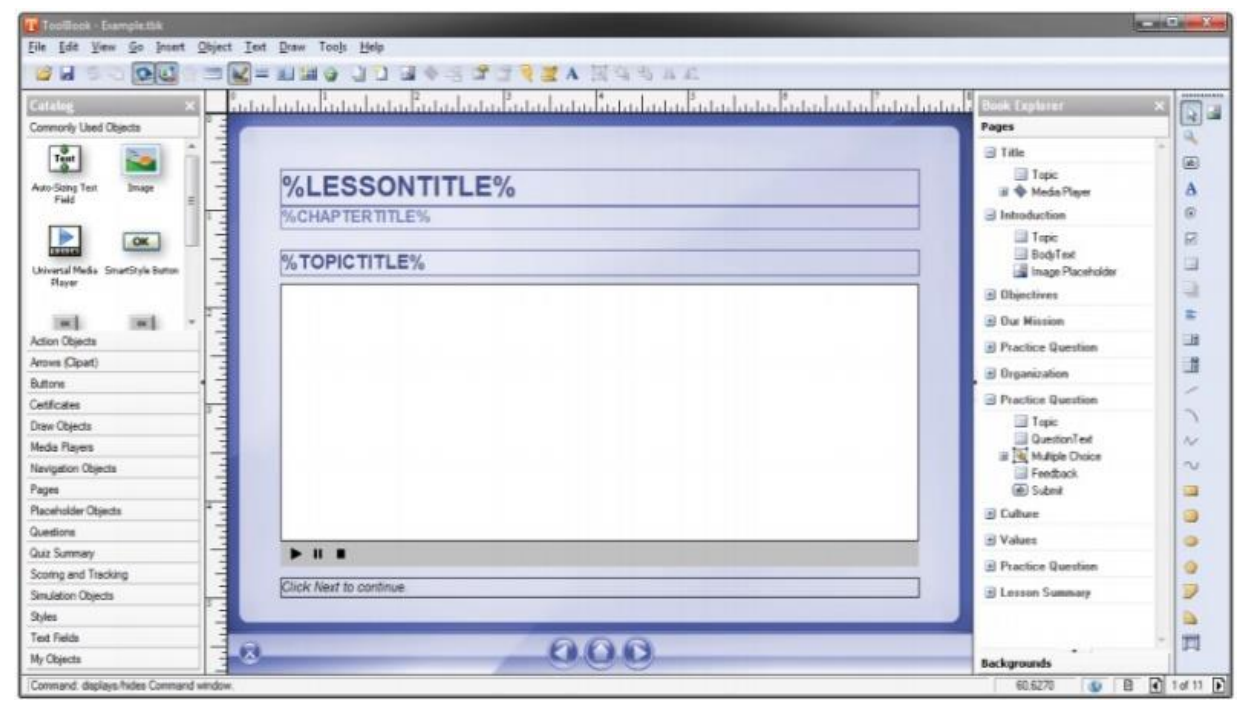

Figure 7. ToolBook Audio production GUI. 


\section{ToolBook Audio production}

The types of sound in the multimedia library include sound, music, and effects. Sound means reading aloud and commentary. Music refers to background music and subject music. Effect sounds are used to press buttons. Audio must have produced with hardware, ie, audio card support. Audio production and processing software has provided with Wave Studio 2.0 provided by Creative. The following method creates the audio and the sound of the multimedia material library. First, Putonghua has recorded on a metal tape, then the audio signal is input to a computer via a recording deck, and the audio signal has digitized for further processing. Music selects the CD player or recording deck to enter the audio signal into the computer and digitize it. Effect sound chooses to save the contents of your hard disk or CD-ROM sound effect library. Figure. 7 shows the ToolBook Audio production GUI.

\section{Production of video images}

In the multimedia material library, the processing of video images can use hardware compression and software playback methods. This method is to collect the video source images with a video card, and then select the corresponding compression standard storage. In addition, in some electronic publications There are many excellent multimedia materials, which should be collected and organized in peacetime, which is also an effective way to improve the production speed and the quality of multimedia material libraries.

\section{Conclusion}

As we all know, the development speed of computer technology is very fast, which requires the computer teachers to continue to learn and grasp the new content in order to adapt to the needs of teaching and scientific research. The computer teachers are the main force for the development of multimedia software in our school. The school should provide them with opportunities to continue learning and the equipment environment for the application, to improve the teaching and application level of computers in our school, and promote the development of multimedia teaching in our school. For non-computer professional teachers, especially young teachers, the school should create environment for them to cultivate their computer application capabilities, so that they can be familiar with the use of computers as a tool to meet the needs of higher education in the $21 \mathrm{st}$ century. In short, with the application of multimedia technology in the field of computer-assisted instruction, multimedia teaching has become an important part of the modernization education of universities and colleges. Only vigorously developing multimedia teaching and accelerating the reform of the teaching system of our university can we make our university among the best modern college.

\section{References}

Alsawaie, O. N., \& Alghazo, I. M. (2010). The effect of video-based approach on prospective teachers' ability to analyze mathematics teaching. Journal of Mathematics Teacher Education, 13(3), 223-241. http://dx.doi.org/10.1007/s10857-009-9138-8 
Babiker, M. E. A. (2015). For effective use of multimedia in education, teachers must develop their own educational multimedia applications. Turkish Online Journal of Educational Technology - TOJET, 14(4), 62-68. https://www.learntechlib.org/p/175095/.

Brutus, S., \& Livers, A. (2010). Networking characteristics of African-American managers: Empirical validation and training applications. International Journal of Training \& Development, 4(4), 287-294. http://dx.doi.org/10.1111/1468-2419.00114

Canclini, N. G. (2013). Precarious creativity: Youth in a post-industrial culture. Journal of Latin American Cultural Studies, 22(4), 341-352. http://dx.doi.org/10.1080/13569325.2013.847566

Cassino, R., Tucci, M., Vitiello, G., \& Francese, R. (2015). Empirical validation of an automatic usability evaluation method. Journal of Visual Languages \& Computing, 28, 1-22. http://dx.doi.org/10.1016/j.jvlc.2014.12.002

Daniel, M., Fowler, R., Merritt, C., Raukar, N., Sutton, E., Allen, G., \& Clyne, B. (2018). Creating effective and engaging presentations. The Clinical Teacher, 15(3), 191-196. https://doi.org/10.1111/tct.12712

Jahangiri, K., \& Abilipour, I. (2014). Effects of collaboration and exercise type on incidental vocabulary learning: evidence against involvement load hypothesis. Procedia - Social and Behavioral Sciences, 98, 704-712. http://dx.doi.org/10.1016/j.sbspro.2014.03.471

John, M., Ray, C., \& Sun, T. (2013). Value-based consumer segmentation: The key to sustainable agri-food chains. British Food Journal, 115(9), 1313-1328. http://dx.doi.org/10.1108/BFJ-09-2011-0215

Nuninger, W., \& Châtelet, J. M. (2018). Continuous Learning through Video-Based Courses: The Key to Sustainable Use of Multimedia. International Journal of Distance Education Technologies (IJDET), 16(1), 24-44. http://dx.doi.org/10.4018/IJDET.2018010102

Park, S. Y., Kim, S. W., Cha, S. B., \& Nam, M. W. (2014). Comparing learning outcomes of video-based elearning with face-to-face lectures of agricultural engineering courses in Korean agricultural high schools. Interactive Learning Environments, 22(4), 418-428. https://doi.org/10.1080/10494820.2012.680967

Svirko, E., \& Mellanby, J. (2017). Teaching neuroanatomy using computer-aided learning: What makes for successful outcomes. Anatomical Sciences Education, 10(6), 560-569. http://dx.doi.org/10.1002/ase.1694

Usai, F., O'Neil, K. G., \& Newman, A. J. (2018). Design and empirical validation of effectiveness of LANGA, an online game-based platform for second language learning. IEEE Transactions on Learning Technologies, 11(1), 107-114. http://dx.doi.org/ 10.1109/TLT.2017.2762688

Vatansever, F., \& Yalcin, N. A. (2017). e-Signals\&Systems: A web-based educational tool for signals and systems. Computer Applications in Engineering Education, 25(4), 625-641. https://doi.org/10.1002/cae.21826

Virko, E., \& Mellanby, J. (2017). Teaching neuroanatomy using computer-aided learning: What makes for successful outcomes. Anatomical Sciences Education, 10(6), 560-569. http://dx.doi.org/10.1002/ase.1694 